\title{
Resisting the historical objections to realism: Is Doppelt's a viable solution?
}

\author{
Mario Alai ${ }^{1}$
}

Received: 21 July 2015 / Accepted: 30 March 2016

(C) Springer Science+Business Media Dordrecht 2016

\begin{abstract}
There are two possible realist defense strategies against the pessimistic meta-induction and Laudan's meta-modus tollens: the selective strategy, claiming that discarded theories are partially true, and the discontinuity strategy, denying that pessimism about past theories can be extended to current ones. A radical version of discontinuity realism is proposed by Gerald Doppelt: rather than discriminating between true and false components within theories, he holds that superseded theories cannot be shown to be even partially true (except insofar they agree with current ones), while present best theories are demonstrably completely true. I argue that this position, running counter both the cumulativity of science and fallibilism, is untenable; it cannot account for the success of past theories, nor for the failures of current theories, and rather than shutting the door to the pessimistic historical objections it opens it wide. The best strategy, instead, joins the selective idea there was both some truth and some falsity in discarded theories, like in current ones, with the moderate discontinuity idea that the truth rate in present best theories is much greater than in past ones.
\end{abstract}

Keywords Gerald Doppelt - Best theory realism - Selective realisms - Pessimistic meta-induction $\cdot$ No miracles argument $\cdot$ Historical meta-modus tollens

\section{Two pessimistic arguments against realism and two defence strategies}

We can broadly understand scientific realism (ScR; as opposed to van Fraassen's constructive empiricism) as the claim that there can be compelling reasons to believe in the at least partial and/or approximate truth of scientific theories.

Mario Alai

mario.alai@libero.it

1 Department of Pure and Applied Sciences, Università di Urbino Carlo Bo, Cesena, FC, Italy 


\footnotetext{
${ }^{1}$ For instance, Doppelt calls both of them 'pessimistic meta-induction'; Saatsi distinguishes them, but curiously he calls the meta-modus tollens (MMT) 'pessimistic meta-induction'.
} NMA

$(\alpha)$ some theories are successful;

$(\beta)$ the best or only explanation of success is truth; therefore

$(\gamma)$ successful theories are most probably true; therefore

( $\delta)$ there can be compelling reasons to believe that theories are true (ScR).

But there are two important arguments against realism from the failures of past science. They move from a similar premise and are strictly connected, so that many confuse them under the name of "pessimistic meta-induction" ; but they are distinct and have different conclusions. The former, which more properly deserves that name, is:

PMI

(I) most past successful theories were radically false;

(II) there is no radical (epistemic, methodological, or other) difference between past and present theories;

therefore, by induction

(III) also current and future successful theories are and will most likely be radically false; therefore

(IV) there is no compelling reason to believe that theories are true (in fact, there are reasons to believe that they are mostly radically false).

PMI was famously formulated by Poincaré (1902, p. 160) and Putnam (1978, p. 25). It has the typical form of induction, and its conclusion directly contradicts ScR. The latter antirealistic argument from past failures of science is

MMT

(A) many past successful theories were radically false (=not true); therefore

(B) truth is not the best or only explanation of success; therefore

(C) the NMA does not offer compelling reason to believe that theories are true.

This argument has been proposed by Laudan (1981) and in a particularly cogent form by Lyons (2002). Its conclusion does not contradict ScR, but only premise $(\beta)$ and so the cogency of the NMA. Thus, if it succeeds we lose one argument for ScR, but ScR might still be true. Moreover, it is not inductive, but deductive. Lyons (2002) called it "meta-modus tollens" (MMT), because in the NMA $(\beta)$ entails $(\gamma)$, and MMT rejects $(\beta)$, via modus tollens by denying $(\gamma)$.

Realists have various replies to these attacks, but since PMI and MMT are different, not each reply is equally effective against both; besides, each reply works by qualifying the broad characterization of ScR in one way or another; so, its success does not depend only on how well it resists PMI and/or MMT, but also on how plausible is the form of realism it configures; finally, these replies can be subsumed under two broad strategies, the selective strategy and the discontinuity strategy:

ScR is notoriously supported by the "no miracle" argument (NMA): 
- The selective strategy claims that although the rejected but successful theories may have been partly false, they were not radically false, in the sense that they included some significant true assumptions or components. So it rejects the first premise of PMI and MMT, the radical falsity of past theories. Hence, PMI can conclude at most that theories are partly false. As a result, selective realists stress the continuity between past and present or future science, moderating both the pessimism about past theories, and the optimism about present and future ones.

- The discontinuity strategy rejects PMI (II), holding that since there are marked differences between past and present science, no inductive inference from the former to the latter is possible; because of these differences, also MMT (B) (i.e., that truth is not the only explanation of success) applies only to past science, and the NMA remains valid for current science. As a result, discontinuity realists tend to be quite resigned about past theories, but markedly optimistic about future ones.

The two strategies can be followed in more or less radical ways, and in this section I will just offer a brief overview of the various positions. After that, my main focus will be analyzing and criticizing a particularly structured and radical version of discontinuity realism, proposed by Gerald Doppelt. Eventually, I shall suggest that moderate versions of the two strategies need not be incompatible, and the best stand is probably a balanced position with elements from both strategies.

The selective strategy is mainly represented by structural realism and deployment realism. The former argues that discarded but successful theories got right at least some mathematical structures of the unobservable reality, and that explains their success (Worrall 1989; Ladyman and Ross 2007). Deployment realism, instead, maintains that theories which are false overall have nonetheless some true assumptions, those which were needed to derive the theory's successful predictions, and are preserved in successor theories (Kitcher 1993, pp. 140-149; Psillos 1999).

Another sort of selective strategy holds that even false theories may be (more or less) "verisimilar", or "close" to the truth (Popper 1963; Oddie 1986; Niiniluoto 1987). This means either that theories include some true statements, or that false statements can have some true content. For instance, (1) "all swans are white" and (2) "all swans are black" are both false, but part of the content of (1) is the entailed statement "all swans except Australian swans are white", which is true and explains the predictive success of (1) (Musgrave 2006-2007). Equally, "Approximate truth is a species of partial truth, since the approximations in question are logical parts of what we began with. 'It is 4 o'clock' logically implies 'It is approximately 4 o'clock' as well as 'It is 4 o'clock give or take 5 minutes'" (ibid.).

Rescher (1987, Chap. 5) follows a similar line when he distinguishes between forefront science, which is precise and never true, and "schoolbook science", which in its vagueness and imprecision includes a true core of the former.

Finally, there is the idea that theories must not be taken as true for all the phenomena, but only for certain ranges of phenomena, levels of approximation, or domains of entities which are defined by the theory itself. ${ }^{2}$ This can be interpreted as the selectivist

\footnotetext{
2 See Heisenberg (1955, p. 20), and Agazzi (2014, pp. 310-311, 403-407). According to Kuhn (1962, Chap. 9) this approach was "prevailing" in his time.
} 
thesis that theories which are radically false overall, nonetheless include descriptions which are approximately true for the relevant domains or scales.

The discontinuity strategy, instead, has an antecedent in a simplistic conception of scientific progress, lingering in Positivism and in some scientists at the end of nineteenth century (perhaps even later). It was exemplified by Albert Michelson, who in 1894 stated: “ $\ldots$ it seems probable that most of the grand underlying principles have been firmly established ... An eminent physicist remarked that the future truths of physical science are to be looked for in the sixth place of decimals". 3 This view was probably based on three ideas: the idea of science as mainly empirical and inductive, so that errors are due to contingent mistakes or biases (e.g., Bacon's idola) and can be easily spotted and eliminated, while the truth may be easily found once the appropriate observation instruments and techniques become available; the belief that good scientific method was discovered once for all (by Galileo, Descartes, and Newton), it is not influenced by scientific advancements, and it has been applied widely and long enough to carry us close the whole truth; the disposition to look at the history of science from the vantage point of current theories (criticized in Kuhn 1962, IX) by stressing similarities and overlooking differences (for instance, viewing Newton's laws as special cases of Einstein's laws, or classical mass as the same concept as relativistic mass). Of course one shouldn't overemphasize differences, either (Putnam 1975, pp. 235-238). But by ignoring the radical nature of theoretical change, past theories are read as simply containing a few of the truths of current theories, plus various falsities. So the history of science is seen merely as a progressive elimination of errors terminating only today or in a very near future: all past theories are more or less wrong, while current ones are approximately true.

The most apparent mistakes of this conception have been exposed (among others) by Poincaré, Popper and Kuhn; but there are some right intuitions in it, which even in our days have been exploited to defend realism from the PMI and/or MMT by marking some kind of discontinuity between past and present science.

For instance, Hardin and Rosenberg (1982) claimed that many false theories of the past (like the Ptolemaic cosmology and humoral medicine) were not products of mature science, so from their falsity we cannot infer to the falsity of theories in mature science. This a rather weak defence, for there were many false theories even in mature science (Newton's gravitation theory, Fresnel's wave theory of light, Rutherford's model of the atom, etc.). But according to Ladyman (2002, § 8, 1.3.1) a science is mature only if it is coherent with the fundamental principles of the other sciences, obeys a well entrenched set of fundamental principles defining the domain of science and its methods, and theories of one domain serve as background for theories of different domains. For instance, all branches of contemporary physics presuppose the conservation of energy, the fundamental structure of matter, the concepts of force, mass, charge, velocity, etc. So, it might be argued that none of the failed theories cited by Laudan exhibit the degree of sophistication, unification and coherence of contemporary science.

\footnotetext{
${ }^{3}$ A similar statement is commonly attributed to Lord Kelvin, but it is not clear whether he actually made it: Horgan (1996, p. 19).
} 
For many years Devitt (1984, pp. 143-149; 2005, p. 787) has stressed that progress in scientific methodology, observation instruments and experimental technology continuously improve the reliability of theoretical science, so past failures should not be projected onto the present or the future. For instance, Dorato (2007, p. 181) correctly pointed out that ether and phlogiston were never measured, while we can measure many quantitative properties of the entities we now believe in.

More recently, Fahrbach has countered the PMI by arguing that "our current best theories enjoy far higher degrees of success than any of the successful but refuted theories of the past" (2011, p. 1283). In fact, on the basis of statistical arguments he shows "that three-quarters of all scientific work ever done was done in the last 30-40 years", and the exponential increase in the amount, diversity, and precision of scientific data and amount of computing power marks a sharp difference between current science and anything that was possible more than a few decades ago. Therefore present theories are incomparable to earlier ones as to the number and diversity of the tests successfully passed.

In more general terms also Bird argues against the inductive extrapolation from past failures, because what is called "successful science" is not a unitary kind, supporting induction, but rather a set of practices bearing family resemblances. The PMI might be warranted if the repeated failures in the past could be blamed on some problem shared by all current theories. The most plausible candidate might be the problem of underconsideration, or of unconceived alternatives. But he argues that it is a genuine concern in some cases but not in others (for instance, in fundamental physics, but not in palaeontology) (2015, §3).

An even more radical idea is expressed by science journalist John Horgan in his The End of Science (1996): based on his interviews with front-line scientists, he argues that basic science has now solved all of its main questions. We have now reached the limits of what can be known about the universe, and no more "great 'revelations or revolutions' - no insights into nature as cataclysmic as heliocentrism, evolution, quantum mechanics, relativity, the big bang" are forthcoming. The scientific version of reality of our descendants "will resemble ours, for two reasons: First, ours... is in many respects true; most new knowledge will merely extend and fill in our current maps of reality rather than forcing radical revisions. Second, some major remaining mysteries-Where did the universe come from? How did life begin? How, exactly, does a chunk of meat make a mind? —might be unsolvable" (Horgan 2015). Horgan's former reason is curiously reminding of Michelson's 1894 prediction, and now we shall see that something similar is also the key to Gerald Doppelt' defense of realism.

\section{Doppelt's discontinuity realism}

In a number of papers Doppelt has criticized deployment realism and structural realism, arguing that they can't satisfactorily explain both the predictive and the explanatory success of theories, and above all, they can't resist the PMI and MMT $(2005 ; 2011, \S \S 5$, $6 ; 2014, \S 2) .{ }^{4}$ Against structural realism he claims that appeal to the mere structures

\footnotetext{
4 Although here I discuss papers over a span of 9 years, they appear as developments of a unitary conception, and Doppelt never indicates any change of mind with respect to earlier papers.
} 
is not enough for realists, and not enough to explain the successful predictions of past theories, for they presupposed also ontological assumptions; against deployment realism, instead, he stresses that some false tenets, like those concerning ether or phlogiston, were crucial in deriving the novel predictions of past theories (2007, p. $109 ; 2011$, p. 304, §5, §6;2013, §2, §3; 2014, §1, §2). Thus, as argued by Laudan, from the role played by a claim in a novel prediction one cannot infer its truth (2007, p. 106; 2011, p. 302).

Instead, he proposes a new (and somewhat surprising) brand of realism, called "Best Theory Realism" (BTR), or "Best Current Theory Realism" (BCTR). ${ }^{5}$ It is a radical discontinuity view, which does not discriminate between true and false components of theories, like selective realisms, but between past superseded theories, considered as "false", and present best theories, considered as "true" (2007, p. 112).

In Alai (2014d) I claimed that deployment realism can easily withstand Doppelt's criticisms. Here, instead, I argue that Doppelt's proposal is a dead end: his discrimination between past and present theories is implausibly radical and running counter both the ideas of cumulativity of science and fallibilism; it cannot account for the success of past theories, nor for the failures of current theories; and rather than shutting the door to the PMI and MMT, it opens it wide.

As said, structural and deployment realism are selective strategies, which reply to the PMI and MMT by rejecting premises (I) and (A), viz., the complete or radical falsity of past theories. But Doppelt believes that even if there may be "some true component" in discarded theories, their success cannot be explained by those components: the NMA can convince us of the truth of current theories, but not of superseded theories. So we cannot reject PMI (I) and MMT (A) by asserting the partial truth of discarded theories, as selective realisms try to do.

Instead, he proposes to block the PMI by giving up premise (II) (the methodological and epistemic continuity of past and present science), more or less like other discontinuity approaches (Devitt 1984, pp. 143-149; 2005, p. 787; Fahrbach 2011): current best theories are on a completely different footing from past ones, since (a) they are confirmed by a much greater wealth of phenomena and data, and (b) they fulfil much higher standards of explanatory success. In fact, each successive theory by its own success raises the standards antecedently accepted in its field (2007, pp. 111-112; 2013, p. $49 ; 2014$, p. 286). Hence, current best theories "enjoy a measure of success that differentiate them from their predecessors" (2013, p. 49). Therefore, no inductive inference is possible from (I) the falsity of past theories to (III) the falsity of present ones.

It should be noticed that for Doppelt a theory can have three different kinds of success, which realism should explain: (1) empirical, consisting in empirical adequacy and accuracy of predictions, especially novel predictions; (2) explanatory, consisting in giving the best explanation of phenomena, which involves "simplicity, consilience, the breadth and scope of what it explains, completeness, indirect theoretical support, intuitive plausibility ....and empirical adequacy", plus "internal consistency, consistency with background knowledge ...conceptual intelligibility, and perhaps an appropriate

\footnotetext{
5 As we shall see, this wavering reflects another in the exact content of his doctrine.
} 
mechanism or causal structure" (2005, p. 1081; 2014, p. 288); occasionally he also cites (3) "success in gaining adherents" (2007, p. 110).

The asymmetry between past and present successful theories also blocks the MMT, for the inference from MMT(A) (the falsity of past successful theories) to MMT(B) (that success is not evidence of truth) and $\operatorname{MMT}(\mathrm{C})$ (the failure of the NMA) is warranted only for past theories, and the NMA still works for current theories:

scientific realism stands or falls on its ability to provide the best explanation of the fact that (1) our most successful current theories uniquely succeed in meeting the highest and most reasonable standards of scientific knowledge in the whole field and (2) superseded or rival theories lack this success. The hypothesis that our best current theories are approximately true, and superseded or rival ones are false, provides one essential component of a compelling realist explanation of this fact $(2007,114$; also 2007, 112; 2011, 311).

More precisely, Doppelt distinguishes between (a) current "most successful and well established" (2007, p. 109) or "best" $(2013,2014)$ theories, and (b) once successful but now superseded (or current, but not most-successful-and-well-established) theories. He seems to hold that (a) the former are completely (although only approximately) true, and will never be supplanted by better alternatives (which runs against fallibilism and basic intellectual humility); while (b) the latter cannot be shown to contain any true components which are preserved in present and future science (which contrasts not only with deployment and structural realism, but also with the common views of progress and cumulativity in science) $(2007$, p. 110; 2011, p. 315; 2013, p. 48; 2014, pp. 271, 282).

He also seems to assume that the currently held competitors of present best (i.e., most-successful-and-well-established) theories cannot in turn be most-successful-andwell-established, so they are false. The contrast he draws, therefore, is not between past and present theories, but between the best ones, which are still accepted now, and all the others, which can be either past (like phlogiston theory and Newtons' theory) or present (like e.g., quantum mechanics) (2007, p. 110; 2013, p. 49; 2014, p. 284). In principle, old theories too might be among the best ones, but if so, they wouldn't have been discarded, so in practice all the best theories are present (or perhaps future, as we shall see in $\S 6: 2014$, p. 284).

When contrasting best current theories with rejected or non-best theories, Doppelt describes the former as "true" or "approximately true", and the latter as "false", without further qualifications. This is to say that the former are at least approximately true, and the latter not even approximately true, i.e., radically false. This presupposes that we can distinguish between being basically right, except for some minor detail or some minor quantitative error, and being radically wrong, and we can grant that this distinction is possible, although not a sharp one. So in the following I will understand 'true' as 'at least approximately true', and 'false' as 'radically false'. But a theory, a model, or an assumption may be radically false even when just some of its parts or consequences are (radically) false. Thus, whenever required by clarity, I will call a theory (a model, or a statement) completely true when all of its parts are at least approximately true; completely false when all of its parts are radically false; and partly 
true or (equivalently) partly false when some of its parts are at least approximately true and some are radically false.

So, when Doppelt contrasts current best theories as "true" with the others as "false", he cannot mean that the former are partly true, and the latter are partly false, for that is the same thing. Rather, he may mean one of the following: (1) the former are completely true, while the latter are at least partly false, or (2) the former are at least partly true, while the latter are completely false, or (3) the former are completely true and the latter are completely false, or (4) the former are largely true, and the latter are largely false. ${ }^{6}$

From some passages he might seem to take discarded theories to be completely false, for he accepts Laudan's point that "we can explain ...the success of superseded theories on the assumption that they were entirely false" (2007, p. 111), and he notices that even "theories with no true or accurate component claims concerning unobservable" can be successful $\left(2011\right.$, p. 313), ${ }^{7}$ and that "attributing literal truth to some of the outdated theories' claims" is "implausible" (2011, p. 312).

However, he does not positively state that old theories have nothing true or nothing which is still preserved today; on the contrary, he acknowledges the presence of some truth in them: "Newtonian physics worked because it got something right" (2013, p. 50); moreover, phlogiston theorists succeeded because "many of their claims turn out to be approximately true ... That there is some structure of unobservable relations responsible for combustion, respiration, and calcination, may be regarded as a true component of phlogiston theory" (2014, p. 280).

$\mathrm{He}$ is not contradicting himself, however: his point is rather that even if and when discarded theories have some true components, we neither can nor need explain their success by such components, hence we cannot use an inference to best explanation to assert the truth of those components:

I am not arguing that there are no continuities across theory-change in highly successful sciences; or that our best current theories do not reveal what outdated theories "got right" and contributed to the cognitive progress of science. Rather, I hope to show that such continuities - whether at the level of theoretical reference, component hypotheses, or formal structures of relations - do not provide adequate explanations of the empirical success of outdated theories ...(2011, p. 297)

So, he rejects

(1) the assumption that the empirical success of scientific theories is primarily due to, or best explained by, the fact that such theories were saying some true things concerning the unobservable entities, processes, or structural relations in nature; (2) the assumption that these true components ...of superceded theories are identifiable as precisely those features which are preserved and retained in more successful successor theories, including our best current theories (ibid.).

\footnotetext{
6 Interpretation (4) was suggested by Referee \#2. But I shall suggest that (2) is more probably the right one.

7 Both italics are mine.
} 
(See also Doppelt 2007, p. 110; 2011, pp. 302, 311-313; 2014, pp. 271, 282). The success of discarded theories can be explained just by the truth of current ones. For instance, "On the realist assumption that our best current theory-relativity physicsis true, we get a natural and realist explanation of the success of Newtonian mechanics, whether or not we identify true components or accurate mathematical structure in it" (2011, pp. 310, 313). "We can draw on our best current theories in order to explain what outdated theories got right, and why they succeeded, without asserting the truth of any of their theoretical components, supposedly preserved in successful superseding theories" (2013, pp. 47-48; also 2014, p. 274).

Therefore,

"inference-to-the-best-explanation realism exclusively justifies an inference to the truth of our best, most well-established current theories and not any inference to the truth of predecessor theories, their components, structures, or entitiesregardless of how successful they were in their time" (2011, p. 302).

So, Doppelt is committed "to the truth of our best theories, but not to the truth of their successful predecessors, or any components of them" (2014, p. 284). It is precisely by this move that he undercuts Laudan's MMT against realism: because of the discontinuity between past and present theories, the objections against the NMA from success to the truth of discarded theories do not apply to current theories.

In Sect. 3 I shall criticize Doppelt's claim that the success of past theories cannot be explained by their partial truth. At any rate, he grants that discarded theories might be partially true, even if there are no reasons to believe that they are. So, he does not mean that (2) past theories are completely false, nor that (3) past theories are completely false and current ones are completely true. Therefore, in order to maintain a sharp discontinuity between past and present science, he must be read as saying either that (1) current best theories are completely true, or that (4) discarded theories are largely false, and best accepted ones are largely true.

Option (4) (that current theories are largely true, and old ones are largely false) is in the spirit of moderate discontinuity approaches, especially Fahrbach's (2011) idea of "degrees" of success. Moreover, it could be used to block the PMI and MMT by holding that past theories had limited success because of their limited true content, while current theories have greater success because they preserve the true components of old theories and add many more. Hence the NMA applies both to the past and to the present, and thanks to the methodological and technological progress the prevalent falsity of discarded theories cannot be projected to current and future theories. Thus, by option (4) one could combine some of the nicest features of selective or "preservative" realism and of discontinuity realism, providing a plausible explanation of past successes while accounting for scientific progress.

Unfortunately, Doppelt's discontinuism is too radical to accept the graduality of option (4), and the following considerations show that he rather holds option (1) (discarded theories are largely false, and current ones are completely true): (i) he wishes to draw "a 'qualitative' distinction between the success of our best current theories and that of their superseded predecessors" (2007, p. 111); in fact, (ii) he never uses gradual-quantitative comparatives, like "true to a much larger degree", or similar, and he never describes current best theories as mostly or largely true. On the 
contrary, (iii) he always calls their status "unique" (2007, pp. 111-115; 2011, pp. $303,311-312$; 2014, pp. 285-286); moreover (iv) when it comes to explaining their failures he doesn't appeal to what otherwise would be the most obvious explanation, viz., their partial falsity (see Sect.4); besides, (v) option (4) is compatible with the selective approach, which Doppelt explicitly and consistently rejects. Finally, (vi) he claims ${ }^{8}$ that the best current theories will never be superseded by more completely true theories (see Sects. 4-6).

In the next sections I shall discuss the insurmountable problems Doppelt encounters, respectively, in: explaining the success of past and non-best theories (Sect. 3); explaining the failures of current best theories (Sect.4); justifying the unique status of current best theories as completely true and unrevisable (Sects.5-6); and facing the PMI and MMT (Sects. 5-7).

\section{Explaining the success of discarded theories}

According to Doppelt, even if superseded theories were at least partially true, their explanatory and predictive success could not be explained by their partial truth. Rather, we should explain it by three factors: (a) the theoretical and empirical virtues of the superseded theories, (b) their ability "to raise the standards of empirical success for all subsequent theories" (2011, pp. 303,306), and (c) the truth of current best theories. Let's analyze these points separately.

Beginning with (a), for Doppelt the correct predictions and the success in gaining adherents of a false theory like Newtonian physics can be explained "in terms of the stunning unification, simplicity, and empirical adequacy exhibited by the theory, in the context of what was then known about the observed world" (2007, p. 110; also 2011, pp. 302-303).

However, all the theoretical and empirical virtues of the Newtonian theory may explain why it was widely accepted, and why the explanation it gave of various phenomena was a good one (i.e., plausible, informative, comprehensive, etc.). That is, they can explain its success in Doppelt's senses (2) and (3), and also its empirical adequacy, which is part of sense (1). But they cannot explain another key element of sense (1), the theory's novel predictions ${ }^{9}$ (for example, its role in predicting the existence of Neptune). In fact, if one produced a beautifully virtuous but completely false theory (which is possible, if the theorist is sufficiently ingenious), it would be a miracle if that theory also made novel predictions. Novel predictions can be explained only by showing that the theoretical claims essential to their derivation were true (Psillos 1999, p. 104 ff.; Alai 2014a, 2014c). From this point of view they are radically different from the predictions of known phenomena, which can be made even by false theories, if the theorists decide to account for those phenomena, and are patient and ingenious enough to accommodate them. Theoretical virtues, instead, can explain novel predictive suc-

\footnotetext{
8 Although after some wavering, as I will notice.

9 Including novel retrodictions, or novel explanations: i.e., the derivations of previously known phenomena which were not used in building the theory: see Alai (2014a).
} 
cess only indirectly, to the extent that they are more or less probable indications of partial truth.

Notice that Doppelt is in debt of an explanation of novel predictions, for they are the most startling form of success; indeed they are the only explanandum which can properly serve for the NMA, for other kinds of success can be explained even without truth. In fact, Doppelt recognizes this debt, and believes he can honour it (e.g., 2011, pp. 295, 297-298, 300, 313, 314). So, his explanation (a) is insufficient.

As to purported explanation (b), to begin with, it is questionable that each successive theory always raises the standards of success in its field: for instance, Kuhn and Feyerabend argued that scientific revolutions simply change such standards in ways which cannot be comparatively evaluated. ${ }^{10}$ But even when this happens, it is mysterious how a theory's ability to raise scientific standards may explain its success in any of Doppelt's three senses: setting higher standards for empirical success or for explanatory power is not enough to actually get more empirical success or better explanations: it takes a better theory (one with more true content and theoretical virtues), which can live up to those standards. Equally, setting higher standards is not enough to get more adherents, for unless the theory is also up to those standards, people will think they are unrealistic. So, if there exists an explanatory relation between higher standards and the three kinds of success, it is in the opposite sense: precisely because the theory gets more empirical, explanatory and social success, it sets itself as a paradigm, imposing its own empirical, theoretical and methodological virtues as the new required standards.

Doppelt's third proposed explanans for the success of discarded theories is (c) the truth of current ones: "we can draw on our best current theories in order to explain what outdated theories got right, and why they succeeded, without asserting the truth of any of their theoretical components, supposedly preserved in successful superseding theories" (2013, pp. 47-48; also, 2014, §3, pp. 280, 285). For instance, "our best current theories (relativity physics) show why Newton's laws work for a more limited set of circumstances than their truth would require" (2007, p. 111); current electromagnetic theory explains that undulatory ether theories were successful because they described some properties of the electromagnetic field (2013, p. 48; 2014, pp. 281-282); phlogiston theory scored various successes because it saw that combustion, respiration and calcination are the same kind of reaction, and current chemistry explains why (viz., because they are all instances of oxidation) (2011, p. 308; also: 2014, pp. 274, 279).

But this is to say that current best theories explain the (empirical) success of discarded ones only to the extent that they show that the latter were partly true. In fact, contrary to his claim, in these passages Doppelt explains the successes of electromagnetic and phlogiston theories just by asserting the truth some of their theoretical components.

Perhaps his point is that there is no "literal truth" in discarded theories (2011, p. 312) because even if they describe some real properties or structures, they "mischaracterize" them, and their true nature must be learned from current theories:

10 I owe this comment to Reviewer \#3. 
11 Instead, if it is not adopted, the theory cannot be considered successful at all, except in merely rephrasing known empirical regularities: Alai (2014b), §6. from our best theories the true nature of the unobservable structure that is simply assumed and also mischaracterized by phlogiston chemists, but is in fact responsible for the observable phenomena they predicted (2014, p. 279).

But as noticed by Musgrave (2006-2007), even false descriptions may entail weaker but true descriptions, which must be considered as parts of their content. For instance, Newton's false claim that

(i) mass is inalterable

entails the true claim that

(ii) at ordinary velocities mass changes are below a noticeable threshold;

so, (ii) is part of the logical content of Newton's theory; moreover, current physics explains Newton's predictive successes just by showing that (ii) is true and entailed by Newton's theory; i.e., by showing that the latter was partly true.

The same holds for Doppelt's other examples. For instance, he grants that phlogiston theory predicted and explained various phenomena; but since those predictions and explanations are given in terms of its phlogiston vocabulary, they are correct only under a benevolent reinterpretation of that vocabulary (e.g., by interpreting 'phlogiston' as 'lack of oxygen', and 'inflammable air' as 'hydrogen'). However, if this interpretation is adopted, then also some of the principles of the theory turn out true. ${ }^{11}$ Equally, saying that ether theories succeeded because they described some properties of the electromagnetic field and their causal role, is to say that they were right about this description, although they were wrong about the bearer of those properties.

In fact, sometimes Doppelt himself explicitly phrases his explanation of success by appealing to partial truth: phlogiston theorists succeeded because "many of their claims turn out to be approximately true ... That there is some structure of unobservable relations responsible for combustion, respiration, and calcination, may be regarded as a true component of phlogiston theory" (2014, p. 280).

But of course this contradicts his claims that (a) the success of discarded theories needn't and cannot be explained by their partial truth (2011, p. 297; 2014, p. 71), hence (b) there is no inference to the best explanation from the success of old theories to their partial truth, so that (c) the assumption that they had some true component is "implausible" (2011, p. 312) or "flawed" (2007, pp. 110, 111; 2011, pp. 302, 303, 310$313 ; 2013$, pp. 47-48; 2014, p. 274; etc). Equally, when he accounts for the success of discarded theories by appeal to their tenets which are preserved in successor theories he exploits the very explanation of "preservative" (structural or deployment) realism which he officially rejects $(2011$, p. 297; 2013, p. 48; 2014, pp. 271, 282).

Votsis (2011) and Peters (2014) argue that selective realists should be able to identify the essential and purportedly true components of past theories prospectively, from the contemporary point of view. The reason is that for selective realists there are true constituents in past successful theories which explain their success, and are preserved in current theories; and this allows them to block the MMT and apply the NMA to current theories, concluding that some of their components are true. But if they could

...the predictive success of the phlogiston theory is no miracle once we learn 


\footnotetext{
12 Stanford (2006, Chap. 6) also charges the retrospective truth claims of circularity.

13 This interpretation was also suggested by Referee \#2.

14 My italics.
} which are still accepted today, they would beg the question by unduly assuming that the currently accepted components are true. ${ }^{12}$ theories may include some truths, which are crucial to the explanation of their success, but these can be identified only in hindsight, from the standpoint of our current theories; hence, the selective strategy fails. ${ }^{13}$ For instance, he says that the success of discarded theories can be explained only "once we learn from our best theories the true nature of the unobservable structure" they postulate (2014, p. 279).

"Standard [i.e., deployment] and structural realists have to rely on the truth of our got wrong" (2011, p. 310). So, "I argue against the claim that the best explanations of the success of [past] theories is provided by [prospectively?] identifying their true "On the realist assumption that our best current theory-relativity physics-is true, we [retrospectively?] get a natural and realist explanation of the success of Newtonian mechanics, whether or not we [prospectively?] identify true components or accurate mathematical structure in it" (2011, p. 310). ${ }^{14}$ by appeal to their purportedly true components, and the inference to partial truth as explanation of success is possible for the current theories but not for the old ones (2011, past and present theories even if the former were only largely false, and the latter only largely true: a distinction sharp enough to block the PMI and MMT. success of discarded theories cannot be explained by their truth, but only by the truth the success of a theory $\mathrm{T}$ : in a strong sense it consists in (a) identifying some particular components of $\mathrm{T}$ which are essential to its successful novel predictions, and besides have the best credentials for truth, and (b) explaining that $\mathrm{T}$ is successful thanks to their truth. In a weaker sense, however, the success of T can be explained simply by assuming that it has some true components (even if we cannot identify them) from which its novel predictions were derived; in fact, it would be a miracle if novel predictions (especially if highly precise and unexpected) were derived from false assumptions. prospective explanation is possible, since there are criteria for identifying the probably true components of past theories independently of their preservation today. For instance, for Votsis those components are the "minimally interpreted mathematical cessful predictions and not empirically refuted; for Cordero they are those involved in predictive success, resistant to hostile probing and with outside support. If they

identify the purportedly true components of past theories only retrospectively, as those

In this light, one might charitably interpret Doppelt as holding that superseded best current theories in order to identify what outdated theories got right and what they components ....which are preserved across theory change" (2014, p. 271). Instead,

This argument would then show why the success of past theories cannot be explained p. $302 ; 2014$, p. 284). This would already mark a "qualitative" distinction between

But even if this is Doppelt's argument, I don't think it manages to show that the of current ones. In fact, we must distinguish two senses of (prospectively) explaining

Psillos (1999), Votsis (2011), Peters (2014) and Cordero (2015) argue that strong parts"; for Peters they are the minimal sub-theories which are presupposed by the suc- 
are right, Doppelt's supposed argument that the explanation of success can only be retrospective fails. But while their arguments are prima facie plausible, they crucially rely on the notion of what is essential to a prediction, and this partly depends on the theorists' collateral assumptions, which vary continuously from time to time. Even today, while trusting that current theories are largely true, we admit that there are probably many mistakes in them, but what exactly is wrong-so also what is true-we can only hypothesize, and only future science will tell. The same of course applied to past scientists at their own time. So, it is hard to say whether a strong explanation of success can be given prospectively.

But we don't need to decide this difficult question here, because even if the strong explanation could not be given prospectively, the weak explanation can: if 200 years ago a theorist got right a novel and bold prediction, she could already reasonably assume, by the NMA, that her theory had struck some important truth, even if she could not be sure what exactly was true and what was false in it. So, she could give a weak prospective explanation of her success. Clearly, the same applies to today's theories. Now, this is enough for scientific realists, for they are not committed to the truth of this or that particular assumption (which is rather the scientists' task), but only to the possibility of having justified beliefs in the at least partial (approximate) truth of theories. So there is no basic difference in how we get confidence in our theories today, and past scientists got confidence in their own. Moreover, if the success of discarded theories could be explained only in hindsight, the same would hold for current ones. Hence, even the charitable interpretation of Doppelt's argument I have considered here fails to establish any radical asymmetry between past and present theories.

\section{Explaining the failures of best current theories}

The second problem with Doppelt's reconstruction of realism is how he accounts for the failures of best current theories. As I mentioned, he makes no use of the prima facie most plausible explanation, i.e., that they are partly false: this confirms that he assumes they are completely true. Instead, first of all he accepts as true only our "best" or most-successful-and-well-established theories. He does not give a list of such theories or formal criteria for qualifying as such, but "most successful" is usually paraphrased as (i) standing "at the pinnacle of predictive success in the entire field of inquiry" and (ii) providing "the best explanation of the predictive success of its predecessors and of its own distinctive success" (2014, pp. 287-288). ${ }^{15}$ "Wellestablished", instead, mainly refers to coherence with other accepted theories, but also (again) to explanatory effectiveness, intuitive plausibility, and internal coherence. For instance, quantum mechanics is not one of the best theories, because it is predictively successful but (a) lacks explanatory success, internal coherence, intuitive plausibility, and (b) it is incompatible with another accepted theory, special relativity (2007, pp. $100,103,109-110 ; 2011$, p. $315 ; 2014$, pp. 288-289).

\footnotetext{
15 In Sect. 2 we saw that by "best explanation" he basically means one endowed with the standard theoretical virtues; but this is not crucial here.
} 
16 Doppelt (2014, pp. 287-288). See Sect. 6 below. from those which are just "false". in question" (2007, p. 115; 2011, p. 312). unjustified.

\section{The unique status of current best theories}

But it might be pointed out that by the same token special relativity is incompatible with quantum mechanics, hence it is not well-established either. Thus, one wonders which are the best current theories, if not these, two of the most paradigmatically successful theories, which provide our basic view of the physical world. He seems to take Maxwell's electromagnetic theory (2013, p. 48), general relativity (2007, p. 111; 2011, pp. 303, 310; 2013, p. 50), and current chemistry (2014, pp. 274, 279) as being among our best theories; but "current chemistry" can hardly be considered as one theory, while Maxwell's theory and general relativity too encounter problems and incompatibilities, unless the scope of their application is suitably restricted. So, it is unclear whether there really are theories corresponding to his criteria, and how in actual cases he would distinguish those which in spite of some failures are "true",

Setting this aside, Doppelt holds that the failures of best theories (whichever they are) "can be explained as shortfalls that either will be converted to successes with further scientific inquiry, or will be found to lie outside the scope of the current theory

So, two explanations are given here. The former is that the failures in question do not depend on the theory, but on mistakes in the testing procedure, like wrong background assumptions or experimental inaccuracies, which will be corrected by subsequent research. Now, it is reasonable that some experimental failures are of this kind (like, e.g., the apparent confutation of Newton's theory by the discrepancies of Uranus' orbit, prior to the discovery of Neptune). But claiming a priori that all failures of a current theory are merely apparent as in these cases would be implausible and

Doppelt's second explanation is that the failed predictions will be found to actually lie outside the scope of the theory. But, who is to say which and how broad should be a theory's scope? And would it not narrow down the heuristic and unifying power of a theory, two of the most salient theoretical virtues, if its scope is delimited a priori? Even more, narrowing down its scope ad hoc to get rid of the failed predictions, would be a "degenerating" (Lakatos 1970, §2) move, weakening its explanatory power and casting doubts on the correctness of the basic mechanism postulated by the theory. But this would show that, contrary to Doppelt's assumption, that theory is not mostsuccessful-and-well-established. Besides, if a theory has false consequences, no matter in which area, then it is partly false, against his view of best theories as completely true. One may then drop the false assumptions from which the wrong consequences were drawn, but this again would weaken the theory and suggest that, contrary to his claim, ${ }^{16}$ theories better than our best ones are possible.

Doppelt's account for the failures of current best theories makes clear that he believes there is no falsity in them except some minor inaccuracies or approximations. This is confirmed by his reply to the PMI: current best theories will not be refuted, because 
they have a "unique status" in the history of their discipline, distinguishing them from other theories, since they "stand alone at the pinnacle of the entire field of inquiry" (2014, p. 285), and "they alone realize the highest standards of predictive success and confirmation in the field" (ibi., 286. Also 2011, p. 311; 2013, p. 49). So, no inference from the falsity of past theories to that of present best ones is possible.

In this way he also replies to Laudan's objection that since some false theories were successful, truth is not the only possible explanation of success (the MMT): the modest successes of past theories can be explained in other ways, but only truth can explain the incomparably greater successes of present theories (2013, p. 49; 2014, pp. 285-286).

But one could object that an item can "stand at the pinnacle", i.e., be the best of a long series, without radically differing from the rest of it: current best theories may be just a tiny little bit better than the past best theories: so, why should they be immune from the PMI? Doppelt answers, like Devitt and other discontinuity theorists, by appealing to the much wider body of data and far more advanced standards and methods on which they are based. But it might be replied that even in the past empirical knowledge and scientific methodology had improved steadily: for instance, they had improved a lot from $1000 \mathrm{AD}$ to $1700 \mathrm{AD}$, yet many wrong theories were still held at that date, and even thereafter. So, is hard to think that any improvement of our background empirical knowledge and methods can at some point make scientists practically infallible; and even more that this point has already been reached.

Fahrbach (2011) shows that in recent years the qualitative and quantitative improvement of scientific work, instruments and available data has been exponential, so to mark a dramatic difference between science in the last 40-50 years or so and in all the past centuries. Still, we should not forget some fundamental unsolved problems, like the incompatibility between quantum mechanics and relativity, or the lack of a grand unified theory: they show that we are not at the end of the road, yet, and future research will introduce basic changes in currently accepted views.

The history of science witnessed many ruptures, or "revolutions", and this is because nature itself, contrary to an ancient proverb, makes leaps and has ruptures: its workings are not the same at different scales or different locations in space or time. For instance, it is (roughly) deterministic at large scales, but indeterministic at small scales; the physical laws today are probably different from those a few instants after the Big Bang; entropy increases over time in the universe as a whole, but it may decrease in local areas or over short time spans.

Mankind starts its inquiry about nature from the time and area in which it is located, and from the scale of magnitude and range of energies to which it has most direct access. But as it moves far in space or time, or to different scales and ranges of energies, often what it has learned about its earlier targets is no longer valid for the new targets. This may happen just because the new targets work in a different way, so what we discover about them is simply added to what we knew about the old targets, as information about different subjects; or it may be that actually even the earlier targets worked in the newly discovered way, but that could not be noticed in their restricted location or at their particular scale.

For instance, the principle of inertia works on the Earth just like in the empty space, but due to the ubiquitous presence of frictions it was recognized only with great 
difficulty; or mass varies with velocity, but this could not be appreciated at ordinary velocities. So, by extending our research to different scales or locations we may learn that our previous theories were strictly speaking wrong: for instance, we discovered that there is no gravitational attraction at distance, that mass is not unalterable, and that there is no radical opposition between matter and energy.

What we learned at the previous scales or locations may still be approximately correct within those limits, not only at the empirical level, but also at the theoretical level: for instance, the planetary model of the atom is still an approximately true description of the unobservable behavior of the atom within a certain range of phenomena. Yet, in these cases the old models are replaced by, and embedded into, radically different models, which explain the success of the old theories and show what was true in them and what was false. For instance, the heliocentric model supplanted the geocentric one, and the curvature of space supplanted gravitational attraction.

Although we have already greatly expanded our understanding of nature, there are still undiscovered territories in front of us (think for instance of dark matter and energy). So, it is likely that, like in the past, any breakthrough into a new location, scale or range of energies will teach us some new fundamental features of nature, showing that current theories have certain basic mistakes and must be substituted by more fundamental and comprehensive accounts. In fact, the increasingly powerful resources of current science may make such revolutionary changes even more frequent than in the past.

On the other hand, as we proceed further and further from the areas, scales and ranges of energies with which are more familiar, research becomes more and more difficult and demanding. For instance, the energies required to probe the most basic particles, or the states of the universe closest to the Big Bang, grow exponentially, up to the point of escaping present or foreseeable technology. So, even the unprecedented improvement of our scientific resources and methods is insufficient to get us a completely safe grasp of the phenomena on today's frontiers of research and assure that current theories won't be superseded. Therefore, the "gradual" discontinuity approach of Fahrbach and others can block the PMI conclusion that current theories might be completely false, but it cannot show they are immune from revision or substitution.

On the contrary, this is precisely Doppelt's radical discontinuity claim: current theories will not be superseded by theories that are true to an even larger degree. In fact, he acknowledges the following as a possible objection to his position: even in the past some theories were at the pinnacle of inquiry, for they fulfilled the highest standards of their times and enjoyed an unprecedented measure of success; yet they were superseded with the introduction of even higher standards and more successful theories. So, could not also current theories, though fulfilling today's highest standards, be eventually discarded in the face of still higher standards? Thus, he grants, the pessimistic meta-induction is back (2007, pp. 112-113; 2011, p. 312; 2013, p. 49; 2014, pp. 285-286).

Moreover, Doppelt interestingly notices that the PMI can take also an "optimistic" (but equally threatening) form (2005, p. 1077; 2007, p. 113; 2014, p. 286): since scientific standards have been rising at all times in the past, even theories fulfilling the highest standards of their own time have been later replaced by better ones fulfilling higher standards; analogously, even present best theories will probably be replaced 
by better theories. Notice that the "optimistic" meta-induction is not a problem for selective realists, nor for gradual discontinuity realists (at least if they acknowledge that the difficulty of exploring new domains may grow exponentially at the same speed as scientific resources): for they are happy to grant that best current theories, though largely correct, may not be completely true. This however is a problem for Doppelt: for, given his dichotomy between "false" and (completely) "true" theories, if present theories will be replaced by better ones, this means that they are "false". So, the optimistic meta-induction is readily converted into the pessimistic one.

Thus he tries to refute the optimistic meta-induction, countering that "it is far from clear" that today's standards can still be improved (2007, p. 113). But this attempt to shift the burden of proof is illicit, for all our evidence shows that standards have been raising at all times. Doppelt's own claim that methodological improvement increases its velocity in time (2007, p. 111) does not suggest that it will stop today, but that it will progress even faster in the future: hence, current theories, if anything, will cease to be up to the best standards in an even shorter time. Moreover, even in the unlikely event that standards will not rise any longer, the prosecution of research might bring in new empirical data, showing that there are radical mistakes in a theory, although it fulfils the highest possible standards.

Against the threat that our best theories one day might be discarded like past ones, Doppelt also argues that (1) what we should explain is the evidence available to us, (2) the evidence is that "known theories succeed in realizing the most demanding standards of success in the whole history of their field - and their predecessors do not", and (3) "the best explanation of this fact is that our best theories are approximately true, while their predecessors are not" (2014, p. 286. Also 2011, p. 312; 2013, p. 49).

However, our evidence is not that our theories are the most successful in the whole history, but only in the whole history up to now; and part of this evidence is also that many past theories were the most successful in the whole history up to their time, and yet later recognized as false; so, the best global explanation of our evidence is rather that past theories were partly but not completely true, and our theories are largely true, and to a larger degree, but still not completely true.

\section{The best theories so far or ever?}

Faced with these objections, sometimes Doppelt seems ready to retreat to a less ambitious position: after specifying that "the notion of the best theory in a scientific field is entirely independent of its temporal location" (2013, p. 49; 2014, p. 284), he apparently grants that the only theories to whose truth we should be committed might not be ours, but the best of all times, so perhaps still to be found:

If and when [in the future] higher standards and more successful theories appear, this development defeats not scientific realism but rather which theories it is reasonable for the realist to take as approximately true ...Scientific realism need not be committed to the view that we can determine once and for all time which theories it is reasonable to take as approximately true. Rather, the realism defended here is committed to the view that it is reasonable to infer the approximate truth of whichever theories succeed in satisfying the highest standards of predictive 
and explanatory success in the relevant scientific discipline as a whole (2007, p. 114. Also 2011, p. 312; 2013, p. 49; 2014, pp. 286-287).

Perhaps this is why the title of (2014) calls his position 'Best theory realism' (BTR), rather than "Best current theory realism" (BCTR), as the title of (2011).

But this apparently more tenable strategy has its own troubles: it is trivially true that the most-successful-and-best-established theories of all times will never be discarded, but obviously there is no way to tell whether any present or future theory is one of them. Besides, the optimistic meta-induction rears its ugly head again: once Doppelt drops his commitment to the complete and final truth of the theories fulfilling the highest standards of today, granting that they too can be discarded like the past ones (which is plausible), by induction he will be forced to grant that also future best theories might be false and liable to rejection (which is plausible again). But then, given his scepticism on the partial truth of rejected theories, he won't be able to make any commitment to any theoretical truth at any time: which makes for a quite poor form of realism. Moreover, he won't anymore be able to use his advertised explanation of the success of both past and present science, viz., the complete truth of current best theories.

In fact, he eventually gives up this bankrupt strategy, granting that

The realist might retreat to a version of BTR realism which simply asserts the truth of the best theory, independently of whether or not we happen to know what it is. But this move would make BTR a vacuous realism without any substantive commitment to the truth of any theoretical claims in science. This is not a position worth defending and not the one I want to defend (2014, p. 287).

So, he concludes that we can believe in the final truth of the best existing theories, in the sense that (a) they are approximately true, and (b) there are no theories which are still unknown to us, incompatible with them, and more approximately or completely true than them (2014, p. 287). But this view is surprising and implausible: it flies in the face of the fallibilist intuition that all science is inherently subject to errors; it reminds of Hegel's incredible assumption that the philosophy of his own time (indeed, his own philosophy) was the final completion of the spirit's development, the apogee of the whole history; it implies that scientific progress has already come to an end, and from now on it will proceed only by minor adjustments, or by addition of new knowledge on different subjects, without any radical improvement with respect to presently accepted theories and beliefs; so, it assigns present science an astonishing unique status in history.

Doppelt supports his claim as follows: as we saw in Sect. 4, he maintains that we should be committed only to the truth of the best theory in a field, i.e., that which (i) "stands at the pinnacle of predictive success in the entire field", (ii) "provides the best explanation of the predictive success of its predecessors and of its own distinctive success" ${ }^{17}$ and (iii) is coherent with other accepted theories. Now, it may happen that one day our best current theory $\mathrm{T}_{1}$ is superseded by an incompatible and predictively more successful theory $T_{2}$. But this would not show that $T_{2}$ is true and $T_{1}$ is false,

17 In Sect. 2 we saw that by "best explanation" he basically means one endowed with the standard theoretical virtues; but this is not crucial here. 
because $T_{2}$ might not be equally good in explanation; so it could perhaps be used instead of $\mathrm{T}_{1}$, but not considered as approximately true (2014, pp. 287-288). An example is current quantum theory, which is predictively very successful, but a failure from the explanatory point of view, since it is internally inconsistent (admitting both a deterministic and an indeterministic dynamics), inconsistent with the relativity theory, and open to different incompatible interpretations. This is why it cannot be true (2007, p. 100; 2014, pp. 288-289).

Here Doppelt forgets that quantum theory could not be so successful in prediction if it were not at least partially true (Alai 2014c); moreover, in spite of its explanatory failures, even quantum mechanics accounts very well for a lot of phenomena and many successes of the earlier theories. Predictive and explanatory power are not completely independent of each other, after all. But let's leave this aside, and assume for the sake of the argument that one day we find a theory $\mathrm{T}_{2}$ which is more predictively successful but less explanatorily successful than our best theory $\mathrm{T}_{1}$ : later on we might still find a theory $\mathrm{T}_{3}$ incompatible with $\mathrm{T}_{1}$ that is both predictively and explanatorily better, and so be obliged to acknowledge that $\mathrm{T}_{1}$ is false and abandon it.

Doppelt says that this may, "but ...it may not" happen: as long as the future $\mathrm{T}_{3}$ and its explanatory power are unknown, there is no reason to assume that it would be true (2014, pp. 289-290). But this reply is obviously insufficient, since if current theories might be false and superseded by (more completely) true theories, then they are not so radically different from past ones, hence the PMI and MMT apply to them. After all, the history of science shows that sooner or later all theories are displaced by others which are both predictively and explanatorily better. Thus, Doppelt has not shown that current science is the final truth.

\section{Is the PMI fallacious?}

In order to ensure that best current theories will not be rejected, Doppelt also tries to argue that the PMI is incoherent. Other realists have charged the PMI and/or MMT of being fallacious, for one reason or another (Lange 2002; Lewis 2001). In particular, Rescher (1987, p. 61) claimed that the PMI cannot be an argument against the existence of unobservable entities in general, for we decide that certain putative entities do not exist only when we subscribe to a different and incompatible ontology. Similarly, Doppelt argues that the PMI's conclusion (III) that current best theories are entirely false is based on the premise (I) that past theories were entirely false; but we accept (I) because this is what best current theories say. So, from (I) we cannot conclude that best current theories are false. For Doppelt, without assuming the truth of current theories, we could only say that past theories were successful but rejected, and conclude that also current successful theories will be rejected. But this conclusion would not contradict ScR, for it says nothing about truth and falsity.

The supporter of the pessimistic meta-induction will reply that the falsity of past theories is already proven by their empirical failures, quite independently of any belief in current theories. But Doppelt has two rejoinders: (1) Duhem and Quine showed that "there is no such thing as a decisive evidence that a theory is false": a failed prediction simply shows that something in the web of our beliefs is wrong, but this 
is not necessarily the theory under control; (2) Kuhn pointed out that even repeated failures are not taken to refute a theory, until a new theory is adopted (2011, p. 310; 2013, pp. 48-49; 2014, pp. 282-283).

But these two rejoinders are hardly successful: (1) is a mere logical point: although there cannot be logically conclusive falsification, we can gather overwhelming evidence that a theory is false. In fact, as shown by Shapere (1984, p. 223, passim) and others, the various assumptions involved in a failed prediction can be reconsidered one by one in the light of background knowledge and/or of specifically designed tests; thus we can rank them as to their respective doubtfulness or confirmation, and so decide whether the mistake is more probably in one of them, or in the theory under control.

As for Doppelt's rejoinder (2), scientists don't abandon a theory only because one or more "anomalies" emerge, for they trust that the paradigm will succeed in solving those "puzzles". But Kuhn grants that when an anomaly resists repeated attempts of solution, and more and more anomalies emerge, then scientists begin to suspect that something is wrong with the theory, and the paradigm enter a crisis. At this point, clinging to it for faute de mieux, until an alternative is found, is only a pragmatic choice (Kuhn 1962, Chap. IX). So, even for Kuhn a theory can be put in doubt just by empirical results, independently of any other theory.

Besides, the falsity of many past theories is shown not only by their empirical failures, but also by the fact that they are mutually incompatible. Just to take an example, the various theories of the atom introduced in early twentieth century (the cubic model, the plum-pudding model, the Saturnian model, the Rutherford model, and the Bohr model), were incompatible. So, even aside from current theories, one could know that most of them (at least all but one) were false. ${ }^{18}$ Thus, the falsity of past theories [premise (I) of the PMI] can be known by empirical and theoretical considerations, independently of our acceptance of current theories. Hence, Doppelt has not shown that the PMI is incoherent.

\section{Conclusion}

So, I agree with Saatsi (2005) that PMI and MMT are not fallacious, and must be taken seriously (Sect. 7). But all of Doppelt's attempts to escape them fail. In fact, his radical discontinuity realism is even easiest prey to them: by denying premise (II) of the PMI (the methodological continuity of science) he divides up all science into a methodologically safe basket of wholly true theories and a waste basket of unreliable and largely false ones, and then he wavers between two alternatives: (1) either granting that even present best theories might fall into the waste basket, or (2) insisting that current best theories are so successful that no future theory might be predictively and explanatorily better. But in alternative (1), by induction, all science inevitably falls into the waste basket (perhaps except the theories at the Peircean limit of inquiry). Doppelt eventually chooses alternative (2); but against it I have argued that there are

18 Duhem and Laudan also noticed that different accounts of the same phenomena may be equally "successful" (in some sense of the word) and yet incompatible, hence false (perhaps except one): see Cartwright (1983, p. 90), and Saatsi (2005, p. 1089). I owe this suggestion to Reviewer \#2. 
good reasons to suppose that someday also current theories will be substituted by better ones (Sect. 5), and Doppelt has not shown that this will not happen (Sect.6). In addition, we saw that he fails to explain the success of discarded theories without appealing - like selective realists - to their partial truth (Sect. 3), and he cannot provide plausible explanations of the failures of best current theories without granting their partial falsity (Sect. 4).

More generally, the previous considerations show that a radical discontinuity approach cannot provide a plausible form of realism, which at the very least must acknowledge that there is some truth in superseded theories, and something wrong in current theories. For instance, it has recently been pointed out that occasionally science regresses, forgetting important discoveries which then have to be made anew with great efforts (like the correct theory of tides, discovered by Eratosthenes and Seleucus, or Archimedes' infinitary calculus: see Russo 1996, 2003; Netz and Noel 2007). Even if not forgotten, some successful theories (like phlogiston chemistry) are too hastily abandoned after the success of their rivals, so losing some useful conceptual resources or partial truths they contained (Chang 2004, 2012).

On the other hand, even today some disciplines stand on somewhat methodologically weaker bases then paradigmatic disciplines like physics or chemistry. For instance, it has been found that the results of many experimental and statistical studies in psychology and medicine do not stand up to reproduction of the original experiments. Apparently this is not due not to intellectual dishonesty of their authors, but to cognitive biases and methodological mistakes, like data dredging, beside the general premium put on positive (as opposed to negative) and neat results (Shanks et al. 2015; Open Science Collaboration 2015). ${ }^{19}$ If these problems were confirmed and generalized, they would weaken the prima facie impression that contemporary theories stand on incomparably more solid bases than the old ones.

A moderate discontinuity realism, however, may stress the methodological, empirical and theoretical improvements of current science, while granting that it is not yet the end of the road; moreover, as I pointed out in Sect. 2, it could be combined with the selective realist thesis that there is some truth in successful discarded theories, thus providing a very effective reply to the PMI and MMT. Thus, the best realist strategy may be one that reconciles the most flexible versions of these two approaches, although fully elaborating and defending such a position must remain the task for a different paper.

Acknowledgments I am grateful to José Diez, Vincenzo Fano, Carl Hoefer, and Giuliano Torrengo for useful comments on earlier versions of this paper, and to two anonymous reviewers for this Journal for helpful suggestions both on the general structure and on particular issues.

\section{References}

Agazzi, E. (2014). Scientific objectivity and its contexts. Cham: Springer.

Alai, M. (2014a). Novel predictions and the no miracle argument. Erkenntnis, 79(2), 297-326. doi:10.1007/ s10670-013-9495-7.

19 These considerations have been brought to my attention by Reviewer \#3. 
Alai, M. (2014b). Defending deployment realism against alleged counterexamples. In G. Bonino, G. Jesson, \& J. Cumpa (Eds.), Defending realism. Ontological and epistemological investigations (pp. 265-290). Boston-Berlin-Munich: De Gruyter.

Alai, M. (2014c). Why antirealists can’t explain success. In F. Bacchini, S. Caputo \& M. Dell’Utri (Eds.), Metaphysics and ontology without myths (pp. 48-66). Newcastle upon Tyne: Cambridge Scholars Publishing.

Alai, M. (2014d). Deployment vs. Discriminatory realism. In [2014] New thinking about scientific realism (Cape Town, South Africa; 5-9 August 2014), PhilSci Archive. http://philsci-archive.pitt.edu/10551/.

Bird, A. (2015). Is there meta-scientific knowledge? Against both the no-miracles argument and the pessimistic meta-induction. Draft.

Cartwright, N. (1983). How the laws of physics lie. Oxford: Clarendon and Oxford University.

Chang, H. (2004). Inventing temperature: Measurement and scientific progress. New York: Oxford University Press.

Chang, H. (2012). Is water $\mathrm{H}_{2} \mathrm{O}$ ? Evidence, pluralism and realism. Dordrecht: Springer.

Cordero, A. (2015). Retention, truth-content and selective realism. Draft.

Devitt, M. (1984). Realism and truth. Oxford: Blackwell.

Devitt, M. (2005). Scientific realism. In F. Jackson \& M. Smith (Eds.), The Oxford handbook of contemporary philosophy (pp. 767-791). Oxford: University Press.

Doppelt, G. (2005). Empirical success or explanatory success: What does current scientific realism need to explain? Philosophy of Science, 72, 1076-1087.

Doppelt, G. (2007). Reconstructing scientific realism to rebut the pessimistic meta-induction. Philosophy of Science, 74, 96-118.

Doppelt, G. (2011). From standard scientific realism and structural realism to best current theory realism. Journal for General Philosophy of Science, 42, 295-316.

Doppelt, G. (2013). Explaining the success of science: Kuhn and scientific realists. Topoi, 32, 43-51.

Doppelt, G. (2014). Best theory scientific realism. European Journal for Philosophy of Science, 4, $271-291$.

Fahrbach, L. (2011). Theory change and degrees of success. Philosophy of Science, 78, 1283-1292.

Hardin, C., \& Rosenberg, A. (1982). In defence of convergent realism. Philosophy of Science, 49, 604-615. Heisenberg, W. (1955). Das Naturbild der heutigen Physik. Hamburg: Rohwolt.

Horgan, J. (1996). The end of science: Facing the limits of science in the twilight of the scientific age. New York: Broadway Books.

Horgan, J. (2015). Was I wrong about 'The End of Science'? Scientific American. http://blogs. scientificamerican.com/cross-check/was-i-wrong-about-8220-the-end-of-science-8221/.

Kitcher, P. S. (1993). The advancement of science. Oxford: University Press.

Kuhn, T. S. (1962). The structure of scientific revolutions. Chicago: University of Chicago Press.

Ladyman, J. (2002). Understanding philosophy of science. London: Routledge.

Ladyman, J., \& Ross, D. (2007). Chapter 2: Scientific realism, constructive empiricism, and structuralism. In Everything must go: Metaphysics naturalized (pp. 66-129). Oxford: Oxford University Press.

Lakatos, I. (1970). Falsification and the methodology of scientific research programmes. In I. Lakatos \& A. Musgrave (Eds.), Criticism and the growth of knowledge (pp. 91-195). Cambridge, MA: University Press.

Lange, M. (2002). Baseball, pessimistic inductions and the turnover fallacy. Analysis, 62, 281-285.

Laudan, L. (1981). A confutation of convergent realism. Philosophy of Science, 48, 19-49.

Lewis, P. (2001). Why the pessimistic induction is a fallacy. Synthese, 129, 371-380.

Lyons, T. D. (2002). The pessimistic meta-modus ollens. In S. Clarke \& T. D. Lyons (Eds.), Recent themes in the philosophy of science. Scientific realism and commonsense (pp. 63-90). Dordrecht: Kluwer.

Musgrave, A. (2006-2007). The 'Miracle Argument' for scientific realism. The Rutherford Journal, the New Zealand Journal for the History and Philosophy of Science and Technology, 2. http://www. rutherfordjournal.org/article020108.html.

Netz, R., \& Noel, W. (2007). The Archimedes codex: Revealing the secrets of the world's greatest palimpsest. London: Weidenfeld and Nicolson.

Niiniluoto, I. (1987). Truthlikeness. Dordrecht: Reidel.

Oddie, G. (1986). Likeness to truth. Dordrecht: Reidel.

Open Science Collaboration. (2015). Estimating the reproducibility of psychological science. Science, 349(6251). http://science.sciencemag.org/content/349/6251/aac4716.full.

Peters, D. (2014). What elements of successful scientific theories are the correct targets for "selective" scientific realism? Philosophy of Science, 81, 377-397. 
Poincaré, H. (1902). La science et l'hypothèse, Paris : Flammarion. Engl. transl. Science and Hypothesis. New York: Dover Publications 1952.

Popper, K. (1963). Conjectures and refutations: The growth of scientific knowledge. New York: Harper and Row.

Psillos, S. (1999). Scientific realism. How science tracks truth. London: Routledge.

Putnam, H. (1975). The meaning of 'meaning'. In Id., Mind, language and reality (pp. 215-271). Cambridge, MA: Cambridge University Press.

Putnam, H. (1978). Meaning and the moral sciences. London: Routledge and Kegan Paul.

Rescher, N. (1987). Scientific realism: A critical reappraisal. Dordrecht: Reidel.

Russo, L. (1996). La Rivoluzione dimenticata. Milano: Feltrinelli.

Russo, L. (2003). Flussi e riflussi. Milano: Feltrinelli.

Saatsi, J. T. (2005). On the pessimistic induction and two fallacies. Philosophy of Science, 72, 1088-1098.

Shanks, D. R., Vadillo, M. A., Riedel, B., Clymo, A., Govind, S., Hickin, N., et al. (2015). Romance, risk, and replication: Can consumer choices and risk-taking be primed by mating motives? Journal of Experimental Psychology: General, 144(6), e142-e158.

Shapere, D. (1984). Reason and the search for knowledge. Boston studies in the philosophy of science (Vol. 78). Dordrecht: Reidel.

Stanford, P. K. (2006). Exceeding our grasp: Science, history, and the problem of unconceived alternatives. Oxford: Oxford University Press.

Votsis, I. (2011). The prospective stance in realism. Philosophy of Science, 78, 1223-1234.

Worrall, J. (1989). Structural realism: The best of both worlds? Dialectica, 43, 99-124. 